Cochrane Database of Systematic Reviews

\title{
Means restriction for the prevention of suicide on roads (Review)
}

Okolie C, Hawton K, Lloyd K, Price SF, Dennis M, John A

Okolie C, Hawton K, Lloyd K, Price SF, Dennis M, John A.

Means restriction for the prevention of suicide on roads.

Cochrane Database of Systematic Reviews 2020, Issue 9. Art. No.: CD013738.

DOI: 10.1002/14651858.CD013738.

www.cochranelibrary.com 
HEADER 1

ABSTRACT

PLAIN LANGUAGE SUMMARY

BACKGROUND

OBJECTIVES

METHODS

RESULTS

Figure 1.

DISCUSSION

AUTHORS' CONCLUSIONS

ACKNOWLEDGEMENTS

REFERENCES

CHARACTERISTICS OF STUDIES

APPENDICES

HISTORY

CONTRIBUTIONS OF AUTHORS

DECLARATIONS OF INTEREST

SOURCES OF SUPPORT

INDEX TERMS

\section{TABLE OF CONTENTS}


[Intervention Review]

\title{
Means restriction for the prevention of suicide on roads
}

\author{
Chukwudi Okolie ${ }^{1,2}$, Keith Hawton ${ }^{3}$, Keith Lloyd ${ }^{1}$, Sian F Price ${ }^{4}$, Michael Dennis ${ }^{1}$, Ann John ${ }^{1,2}$
}

1Swansea University Medical School, Swansea, UK. ${ }^{2}$ Public Health Wales, Swansea, UK. ${ }^{3}$ Centre for Suicide Research, Department of Psychiatry, University of Oxford, Oxford, UK. ${ }^{4}$ Public Health Wales Observatory, Public Health Wales, Carmarthen, UK

Contact address: Ann John, a.john@swansea.ac.uk.

Editorial group: Cochrane Common Mental Disorders Group.

Publication status and date: New, published in Issue 9, 2020.

Citation: Okolie C, Hawton K, Lloyd K, Price SF, Dennis M, John A. Means restriction for the prevention of suicide on roads. Cochrane Database of Systematic Reviews 2020, Issue 9. Art. No.: CD013738. DOI: 10.1002/14651858.CD013738.

Copyright $@ 2020$ The Cochrane Collaboration. Published by John Wiley \& Sons, Ltd.

\begin{abstract}
A B S T R A C T

\section{Background}

Road traffic suicides are common. However, due to the difficulty in distinguishing between motor vehicle crash fatalities and actual suicides, no official figures exist for this method of suicide. Restricting access to means is an important universal or population-based approach to suicide prevention with clear evidence of its effectiveness. However, the evidence with respect to means restriction for the prevention of suicide on roads is not well established. We conducted a systematic review to assess the impact of restrictions on the availability of, or access to, means of suicide on roads.
\end{abstract}

\section{Objectives}

To evaluate the effectiveness of interventions to restrict the availability of, or access to, means of suicide on roads.

\section{Search methods}

We searched the Cochrane Library, MEDLINE, Embase, PsycINFO, and the Transport Research International Documentation (TRID) Database from the date of database inception to March 2020. We conducted searches of the World Health Organization International Clinical Trials Registry Platform (ICTRP) and ClinicalTrials.gov to identify unpublished and ongoing studies. We applied no date, language, or publication status restrictions to these searches.

\section{Selection criteria}

Eligible studies were randomised or quasi-randomised controlled trials, controlled intervention studies without randomisation, beforeafter studies, or studies using interrupted time series designs, which evaluated interventions to restrict the availability of, or access to, means of suicide on roads.

\section{Data collection and analysis}

Two review authors screened abstracts and full-text publications against the inclusion criteria. Two review authors planned to independently extract data and assess risk of bias of included studies. However, we identified no studies eligible for inclusion.

\section{Main results}

We identified no studies that met the inclusion criteria for this review.

\section{Authors' conclusions}

This systematic review highlights the paucity of research around road traffic suicides and the need for future robust studies that aim to investigate the effectiveness of interventions to prevent suicide on roads. Suicide ascertainment is a key issue; therefore, clear objective criteria are necessary in order to scale up and study this method more accurately. In the absence of any substantial evidence, we advocate 
for more awareness on road traffic suicides and its inclusion in future government suicide prevention policies. Further research exploring effective measures, particularly those that do not require driver compliance, are also needed.

\section{PLAIN LANGUAGE SUMMARY}

\section{Means restriction to prevent suicide on roads}

\section{Why is this review important?}

Road traffic suicides are difficult to distinguish from motor vehicle crash fatalities and, therefore, no official figures exist for this method of suicide. Limiting access to lethal methods used for suicide (called means restriction) is an important universal or population strategy for preventing suicide. While there is evidence that means restriction is an effective approach for preventing suicides, the evidence for preventing suicide on roads is not well established. Therefore, this review aimed to explore the impact restriction of access would have on suicide on roads.

\section{Searching for evidence}

We searched several medical databases to find studies that assessed the impact of restricting access to means of suicide on roads. We searched the databases up to March 2020. We also searched international trial registries for unpublished and ongoing studies. Our main outcomes of interest were suicide and attempted suicide or self-harm.

\section{Key results}

We found no studies eligible for inclusion in the review. As a result, we cannot draw any conclusions as to the effectiveness of means restriction interventions for the prevention of suicide on roads. Determining suicidal intent is a major problem in road crash fatalities, therefore clear objective criteria are necessary in order to scale up, study and understand this method of suicide more accurately. Improved awareness of suicide on roads in suicide prevention activities is needed, as well as, its inclusion in future government suicide prevention policies. Robust studies investigating the effectiveness of interventions to prevent suicide on roads are urgently required 


\section{B A C K G R O U N D}

\section{Description of the condition}

\section{Suicide rates}

Suicide is recognised as a significant global public health problem. It is estimated that each year around 800,000 people die from suicide; this equates to a global mortality rate of 10.5 per 100,000 population (WHO 2019). However, it is suggested that global suicide figures could be under-reported due to misclassification of suicides as accidents or other causes of death (WHO 2014). Suicide occurs throughout the lifespan and is the second-leading cause of death in 15- to 29-year olds worldwide behind unintentional road injury (WHO 2018). Most deaths by suicide occur in low- and middle-income countries (79\%), however, high-income countries have the highest age-standardised suicide rates (11.5 per 100,000 population) (WHO 2019). Self-harm, which includes acts of selfpoisoning or self-injury carried out by an individual irrespective of motivation or suicidal intent (NICE 2011), is much more common than suicide and a significant cause of morbidity and mortality, including by suicide (Sinclair 2010; WHO 2014). In describing selfharm, we have followed the approach favoured in the UK and some other countries where all purposeful self-harm with or without suicidal intent (from non-suicidal self-injury to suicide attempts) is described and included in a single category, namely self-harm (Hawton 2016).

\section{Risk factors/causes}

There are a variety of risk factors for suicide. These include mental disorders (particularly depression, anxiety, and substance abuse); social, psychological, biological, and genetic factors; exposure to suicide in others; and adverse life events (Hawton 2009; Turecki 2016). A prior suicide attempt is the single most important risk factor for suicide in the general population (WHO 2014). Sex is also a factor, with higher rates of suicide reported in males (13.7 per 100,000 population) than in females ( 7.5 per 100,000 population) (WHO 2019). However, unlike suicide, self-harm usually occurs more commonly in females (Hawton 2008; Geulayov 2016). Whatever the background factors at the point when a person feels hopeless and suicidal, access to the means of suicide can be decisive (Hawton 2007). Availability of means can increase the likelihood of a suicide attempt, particularly where impulsive behaviour is a factor (Hawton 2007). The nature of the method chosen will influence the outcome (Yip 2012).

\section{Definitions}

A range of different terms are used for suicide and suicidal behaviour. In the context of this review, 'suicidal behaviour' refers to any form of intentional self-injurious or self-poisoning behaviour with known suicidal intent. 'Suicide' refers to selfinjurious or self-poisoning behaviour with a fatal outcome and known suicidal intent or where that intent was underdetermined. Self-harm includes acts of self-poisoning or self-injury irrespective of motivation or suicidal intent.

\section{Means of suicide}

Three principal methods of suicide predominate worldwide. These include hanging, use of firearms, and poisoning by ingestion of pesticides (WHO 2014). Road traffic suicides are also known to be quite common and can be categorised as either driver suicides or pedestrian suicides (Routley 2003). Driver suicides are typically single-vehicle, single-occupant collisions and occur by three main methods: driving a vehicle off road infrastructure with the intention of self-harm; driving a vehicle into road infrastructure with the intention of self-harm, or driving a vehicle into another vehicle with the intention of self-harm (Harrison 2017). Likewise, pedestrian suicides occur by: jumping off or on to road infrastructure with the intention of self-harm (this may be from a moving vehicle); stepping into the path of a moving vehicle with the intention of self-harm; or lying before a moving vehicle on a road with the intention of self-harm (Routley 2003; Harrison 2017). In our review on means restriction for the prevention of suicide by jumping (Okolie 2020), we addressed all mechanisms of suicide by jumping - including jumping from a height onto roads. We identified three studies from six articles (Lester 1993; O'Carroll 1994; Beautrais 2001; Beautrais 2009; Sinyor 2010; Sinyor 2017) that evaluated interventions on bridges that spanned (but were not specific to) road networks. There was little focus on the road networks in all three of these studies. We found that the installation of safety barriers on bridges led to a significant reduction in suicide rates by jumping at these sites. Cost-effectiveness analyses suggested that bridge barriers would be highly cost-effective in the long term as a result of reduced suicide mortality by alternate methods.

Researchers have found it difficult to assess the true extent of suicide on the roads. One reason is the difficulty of distinguishing between motor vehicle crash fatalities and actual suicides (Andersson 2015; Harrison 2017). Statistics on reported road traffic accidents in Great Britain show that there were 1793 reported road deaths in 2017 - most of whom were vehicle occupants (Department for Transport 2018). Suicide ascertainment is a major problem in road crash fatalities and, as a result, no official figures exist for this method of suicide. Despite this limitation, various local and national estimates and studies of road traffic suicides have been undertaken to establish the scale of the problem. A review of the literature published in 2012 concluded that over $2 \%$ of traffic crashes are as a result of suicidal behaviours (Pompili 2012). In the UK, the Parliamentary Advisory Council for Transport Safety (PACTS) estimates that at least 50 deaths by suicide per year occur on UK roads (Harrison 2017). A Scottish study of fatal road traffic collisions between 1993 and 2003 reported that 17 cases $(2.8 \%$ of all road traffic fatalities) appeared to be suicides (Wyatt 2009). A similar study in Switzerland identified 53 cases of road traffic suicide between 2000 and 2010 (Gauthier 2015). The authors of the above publications, however, suggested a possible under-reporting of road traffic suicides due to the tendency of investigators to regard all road traffic fatalities as unintentional. Despite the lack of clarity with regards to the scale of road traffic suicide, this method of suicide is unique in the sense that it potentially places others (road users and pedestrians) at risk of death and injury (Wyatt 2009).

Some studies suggest that pedestrian suicides are not as common as driver suicides (Gauthier 2015). Most road traffic suicide victims are males aged between 25 and 34 years, unmarried, in regular employment, with a history of attempted suicide (Hernetkoski 1998; Gauthier 2015). A history of mental illness, particularly depression, and alcohol misuse, either proximal to the incident or longer term, have also been identified as possible risk factors associated with road traffic suicides (Hernetkoski 1998; Routley 2003). 


\section{Description of the intervention}

The choice of suicide method can be influenced by certain factors. For road traffic suicide, these include lethality, financial benefits (insurance compensation), and reduced stigma (than other methods) (Routley 2003). Availability and accessibility of means increases the likelihood of a suicidal act, particularly where impulsive behaviour is a factor (Yip 2012). Restriction of availability or access to lethal methods of suicide (means restriction) is, therefore, an important universal or population-level approach to suicide prevention. Universal prevention strategies are targeted at the general public or entire population groups. These strategies are designed to influence everyone and typically affect people whose suicide risk is otherwise undetected (Yip 2012). Means restriction is underpinned by the concept of intervention being available during acute periods of risk for suicidal behaviour, for example, as might occur when a person with depression is exposed to an adverse life event. If access to means is restricted at this point, the chance of survival beyond the stage of acute risk increases. Evidence from research on near lethal suicide attempts supports the idea that, at least for a proportion of people, these attempts are an impulsive response that would not have occurred if the means had not been readily available (Hawton 2005). Means restriction is therefore applied to the population as a whole, where it typically affects vulnerable individuals, whose suicide risk may be undetected and who have not sought assistance in the midst of this crisis (Yip 2012).

It has been argued that restricting access to one method of suicide will lead to substitution with another. There is evidence, however, that restricting access to means during periods of acute risk can have an impact on an individual's likelihood of dying from suicide in the longer term (Daigle 2005). Studies of substitution suggest that, although there may be some shifting of suicidal acts to other sites, deaths by the same method are still significantly reduced overall (Pirkis 2013).

\section{How the intervention might work}

As a means of suicide, vehicles and road infrastructure are widely available yet population-wide restriction of access to vehicles on the road network is not practical. However, implementation of barriers for high-risk individuals and situations - such as the use of alcohol ignition interlock devices and driver monitoring systems - have been suggested as potential interventions (Routley 2003). Installation of physical barriers and fencing at high-risk jumping sites, especially bridges, has been shown to be effective at reducing the number of suicides by jumping (Okolie 2020). Since barriers and fences provide a physical obstruction to prevent individuals from jumping off or onto structures, this approach may also be relevant in the prevention of suicides on actual road networks particularly pedestrian suicide - by restricting pedestrian access to road networks. These interventions may be used in combination with other suicide prevention measures such as interventions aimed at increasing opportunities for help-seeking (e.g. crisis telephone support services), or those aimed at increasing the opportunity and capacity for human intervention (e.g. closedcircuit television (CCTV) camera surveillance). Some or all these interventions could operate at multiple levels within the universal, selective, and indicated hierarchy as described below.

- Universal interventions: targeted at the general public or whole populations.
- Selective interventions: targeted at individuals or groups within a population at increased risk of suicidal behaviours.

- Indicated interventions: targeted at individuals with known suicidal behaviours.

Most means restriction interventions operate at the universal level. However, where these interventions are targeted at highrisk individuals or installed in proximity to schools, psychiatric hospitals, or prisons, these interventions could then operate at the indicated/selective levels.

Other measures such as responsible media reporting - including not reporting on method and context of a suicide - are also important for suicide prevention when used in combination with means restriction interventions.

\section{Why it is important to do this review}

Although there is clear evidence of the effectiveness of restricting access to lethal means as a suicide prevention measure (Hawton 2001; Mann 2005; Florentine 2010), the evidence with respect to means restriction for the prevention of suicide on roads is not well established. Research into road traffic suicide is very limited. Previous reviews on this topic have either focused on the epidemiology of road traffic suicides (Routley 2003; Pompili 2012), or sought to establish a possible link between single-car crash drivers and suicidal intent (Pompili 2006). No review has specifically addressed the prevention of road traffic suicides. This is an important area given the high levels of suicide rates in men and their use of this method. Hence, we did a systematic review specifically focused on means restriction for prevention of road traffic suicides to support suicide prevention strategies and activities such as that produced by Highways England (Highways England 2017).

\section{O B JECT IVES}

To evaluate the effectiveness of interventions to restrict the availability of, or access to, means of suicide on roads.

\section{METHODS}

\section{Criteria for considering studies for this review}

\section{Types of studies}

We included primary research studies with the following study designs in this review: randomised controlled trials (RCTs), clusterRCTs, cross-over RCTs, and quasi-RCTs (trials in which allocation of participants to study arms is not truly random). Other study types eligible for inclusion included before-after studies, and studies using interrupted time series design. Due to the nature of this area of study, we anticipated that randomised trials would be unlikely, in which case we considered the best available evidence. We considered both published and unpublished studies. However, we excluded publications with no effectiveness data, such as editorials and case reports. All eligible studies were considered regardless of language.

\section{Types of participants}

Adults or children of all ethnicities were eligible for inclusion in the review. Participants included individuals exhibiting self-harm and/ or suicidal behaviour. We also included studies with participants 
diagnosed with a mental disorder, as well as those in which a diagnosis had not been made prior to suicide or attempted suicide.

\section{Types of interventions}

\section{Experimental intervention}

We considered studies assessing the effectiveness of interventions to restrict the availability of, or access to, means of suicide on roads. These include the use of physical barriers or fencing at highrisk sites, implementation of barriers for high-risk individuals or situations, or in-built vehicle systems to detect and avoid collisions.

Some or all these interventions could operate at multiple levels within the universal, selective, and indicated hierarchy.

We excluded studies assessing the effectiveness of:

- interventions aimed at educating professionals or the public about means of suicide;

- interventions to restrict cognitive availability of means of suicide, for example, the impact of media portrayals;

- interventions aimed at improving recognition, screening for risk, treatment, or the understanding of causes and risk factors of suicidal behaviour (including mental illness);

- interventions solely aimed at increasing opportunities for helpseeking or third-party involvement (e.g. studies only assessing the effects of crisis telephone support services or CCTV cameras on road networks).

However, studies assessing means restriction interventions in combination with other suicide prevention measures such as interventions designed to increase help-seeking or third-party involvement or responsible media reporting, were included.

\section{Comparator intervention}

Comparator interventions or control conditions included any other intervention delivered in isolation (e.g. crisis telephone support services or CCTV on road networks), or no intervention. We also included studies with head-to-head comparator interventions (e.g. signage on road networks versus structural changes).

\section{Types of outcome measures}

\section{Primary outcomes}

- Suicide.

- Attempted suicide or self-harm.

- Study withdrawal.

\section{Secondary outcomes}

- Change in hospital admission rates for attempted suicide or selfharm.

- Cost-effectiveness of interventions.

\section{Timing of outcome assessment}

The effects of the interventions are expected to be immediate; however, studies have shown that a short duration of followup (less than two years) following the introduction of a means restriction intervention may not be adequate to detect a change in the rate of suicides (Hawkins 2007; Hawton 2007). Therefore, we considered that for a study to be eligible for inclusion in a meta- analysis, it had to have a postintervention evaluation of at least two years' follow-up for outcome assessment.

\section{Search methods for identification of studies}

\section{Electronic searches}

We searched the following electronic databases on 27 March 2020 (from the dates of inception):

- The Cochrane Library (2020, Issue 3);

- Ovid MEDLINE (1946 onwards);

- Ovid Embase (1974 onwards);

- Ovid PsycINFO (1806 onwards);

- Transport Research International Documentation (TRID) (all years to 27 March 2020).

The search strategies can be found in Appendix 1; Appendix 2; and Appendix 3.

We applied no date, language, or publication status restrictions to these searches. In addition, we searched international trial registries via the World Health Organization (WHO) International Clinical Trials Registry Platform (ICTRP) (www.who.int/ictrp) and ClinicalTrials.gov (clinicaltrials.gov) to identify unpublished and ongoing studies.

\section{Searching other resources}

\section{Grey literature}

We searched the following sources of grey literature.

- OpenGrey (www.opengrey.eu/).

- Google Scholar.

\section{Reference lists}

We intended to handsearch the reference lists of all included studies. We searched the reference lists of all relevant papers known to our team, and the reference lists of relevant systematic reviews.

\section{Correspondence}

We contacted corresponding authors, chief investigators, and subject experts for information on unpublished or ongoing studies, or to request additional study data.

\section{Data collection and analysis}

\section{Selection of studies}

Two review authors ( $\mathrm{CO}$ and $\mathrm{AJ})$ undertook a two-stage screening process. First, both review authors independently assessed all citations from the searches and identified relevant titles and abstracts. In the second stage, both review authors independently assessed full texts of potentially eligible studies to identify studies to be included in the review. We resolved disagreements at either stage through discussion. Where disagreements could not be resolved, we consulted a third review author.

\section{Data extraction and management}

We planned that two review authors ( $\mathrm{CO}$ and $\mathrm{AJ}$ ) would independently extract data from all included studies using a modified version of the Cochrane Public Health Group Data 
Extraction and Assessment Template. Data to be extracted included:

- methods: study design, total duration of study, study setting, withdrawals of the intervention, and dates of the study;

- participants: total number, mean age, gender, ethnicity, comorbidity, inclusion criteria, and exclusion criteria;

- interventions: intervention, comparison;

- outcomes: primary and secondary outcomes specified and collected, time points reported;

- statistical analysis;

- results;

- limitations;

- notes: funding sources and possible conflicts of interest of study authors.

We planned to resolve any disagreements in the first instance by discussion and, where this failed, by referral to a third review author. However, data extraction was not possible as screening of database searches did not reveal any studies suitable for inclusion in the review.

\section{Assessment of risk of bias in included studies}

We planned that two review authors ( $\mathrm{CO}$ and $\mathrm{AJ}$ ) would independently assess the risk of bias of all included studies. We anticipated that our included studies could consist of both randomised and non-randomised studies, therefore our risk of bias criteria were based on Cochrane's 'Risk of bias' assessment tool (Higgins 2019) and the Cochrane Risk Of Bias In Non-randomised Studies of Interventions (ROBINS-I) tool (Sterne 2016a). The ROBINS-I tool is currently available for cohort study designs but adaptations are being developed for other non-randomised study types (Sterne 2016b).

For randomised trials, we planned to make a judgement of 'low risk', 'unclear risk', or 'high risk' of bias for the following domains.

- Random sequence generation.

- Allocation concealment.

- Blinding of participants, personnel, and outcome assessors.

- Incomplete outcome data.

- Selective outcome reporting.

- Other sources of bias.

For non-randomised studies, we planned to make a judgement of 'low risk', 'moderate risk', 'serious risk', or 'critical risk' of bias for the following domains.

- Confounding.

- Selection bias.

- Bias in classification of interventions.

- Bias due to deviations from intended interventions.

- Bias due to missing data.

- Bias in measurement of outcomes.

- Bias in selection of the reported result.

We planned to resolve any disagreements in the first instance by discussion and where this failed, by referral to a third review author.

Means restriction for the prevention of suicide on roads (Review)

Copyright $\odot 2020$ The Cochrane Collaboration. Published by John Wiley \& Sons, Ltd.

\section{Measures of treatment effect}

We planned to report count or rate data by calculating the pooled incidence rate ratio (IRR) using a random-effects Poisson regression analysis. The pooled IRR is the most appropriate effect size for summarising counts of an outcome (e.g. deaths) over a period of time. We selected Poisson regression because the IRR follows a Poisson distribution, that is, the distribution describing independent, random events in a fixed time interval. In addition, Poisson regression estimates the change in suicide incidence from pre- to postintervention, while also assessing both baseline and between-study variability in the intervention effect (Spittal 2015). Where applicable, we planned to summarise studies reporting cost-effectiveness or economic evidence of means restriction interventions using the brief economic commentary framework (Shemilt 2019).

\section{Unit of analysis issues}

\section{Cluster-randomised trials}

For cluster-randomised trials, we planned to adjust sample sizes based on an estimate of the intracluster correlation coefficient (ICC) derived from that trial (if available), from a similar trial, or from a study of a similar population. We planned to undertake sensitivity analyses to assess the impact of including such trials.

\section{Cross-over trials}

For cross-over trials, we planned to include data from the first period of measurement only and analyse study results together with those derived from parallel-group studies.

\section{Studies with multiple treatment groups}

Given the nature of the area of study, it was unlikely that we found any studies with multiple comparators or studies that were not observational in design. However, if such studies had been identified, we planned to combine the arms to create a single pairwise comparison when possible.

\section{Dealing with missing data}

We intended to use intention-to-treat analysis when data were missing for participants who dropped out of trials before completion. When data regarding an outcome of interest were not reported, we planned to contact the authors of publications to obtain missing results.

\section{Assessment of heterogeneity}

We planned to assess heterogeneity between studies using the $\mathrm{I}^{2}$ statistic. This measure describes the percentage of total variation across studies that results from heterogeneity rather than from chance. Thresholds for interpreting the 12 statistic were: $0 \%$ to $40 \%$ - might not be important; $30 \%$ to $60 \%$ - may represent moderate heterogeneity; $50 \%$ to $90 \%$ - may represent substantial heterogeneity; $75 \%$ to $100 \%$ - considerable heterogeneity. Where there was substantial heterogeneity, we planned to explore possible causes. Where not appropriate, we planned to summarise studies in tables and conduct narrative synthesis.

\section{Assessment of reporting biases}

Reporting bias occurs when the decision to publish a research finding is influenced by the direction and significance of its results (Egger 1997). We planned to assess small-study effects and 
potential publication bias using a funnel plot if a meta-analysis included results of at least 10 studies. If required, we planned to conduct sensitivity analyses to explore the robustness of the metaanalysis conclusions to different assumptions about the causes of funnel plot asymmetry.

\section{Data synthesis}

We planned to analyse data using Review Manager 5 (RevMan Web 2019). Where more than one study examined the same intervention, and we judged the study populations and methods as being sufficiently similar, we planned to conduct a meta-analysis using a random-effects Poisson regression model to provide an overall estimate of treatment effect. We planned to report count or rate data by calculating the pooled IRR. Where we deemed metaanalysis inappropriate due to significant heterogeneity, we planned to provide a narrative synthesis of results.

\section{Subgroup analysis and investigation of heterogeneity}

Suicidal behaviour is strongly associated with a history of selfharm or mental disorder. Effect sizes in these high-risk groups are generally higher than in the general population. When data are available, we planned to conduct the following subgroup analyses.

- History of self-harm versus no known history of self-harm.

- Diagnosis of mental disorder versus no known history of mental disorder.

\section{Sensitivity analysis}

For this review, we planned on analysing the effects of excluding studies that were methodologically different from other studies, studies judged to be at high risk of bias across one or more domain(s), and studies that contributed substantial levels of statistical heterogeneity. If the exclusion of these studies did not substantially alter the direction of effect or the precision of the effect estimates, then we planned to include data from these studies in the analysis. For cluster-randomised trials, we planned to undertake sensitivity analyses to assess the impact of including such trials.

\section{Summary of findings and assessment of the certainty of the evidence}

We planned to use the GRADE system to assess the certainty of evidence for each of our main outcomes (suicide and attempted suicide or self-harm) (Schünemann 2011). Using the four standard GRADE levels of evidence (high, moderate, low, and very low) we planned to assign evidence from RCTs an initial certainty rating of high and evidence from observational studies an initial certainty rating of low (Balshem 2011). We planned to upgrade or downgrade these levels based on our judgements regarding risk of bias, precision, consistency, indirectness of study results, and publication bias. We planned to create separate 'Summary of findings' tables for the following comparisons:

- All means restriction interventions (delivered in isolation or in combination with other interventions) to restrict the availability of, or access to, means of suicide on roads.

- Means restriction interventions delivered in isolation to restrict the availability of, or access to, means of suicide on roads.

- Means restriction interventions delivered in combination with other interventions to restrict the availability of, or access to, means of suicide on roads.

\section{RESULTS}

\section{Description of studies}

\section{Results of the search}

The database searches identified 3929 citations. We identified 271 additional citations from other sources. After deduplication, the initial number of citations decreased to 2185 . Of these, we excluded 2149 citations after screening of titles and abstracts. We assessed 36 full-text articles of 34 studies for eligibility. We found no studies that met the inclusion criteria for this review. The results of all searches are presented in a PRISMA flow diagram (Figure 1). 
Figure 1. PRISMA flow diagram. aEvaluated interventions on bridges that may have spanned over (but were not specific to) road networks.

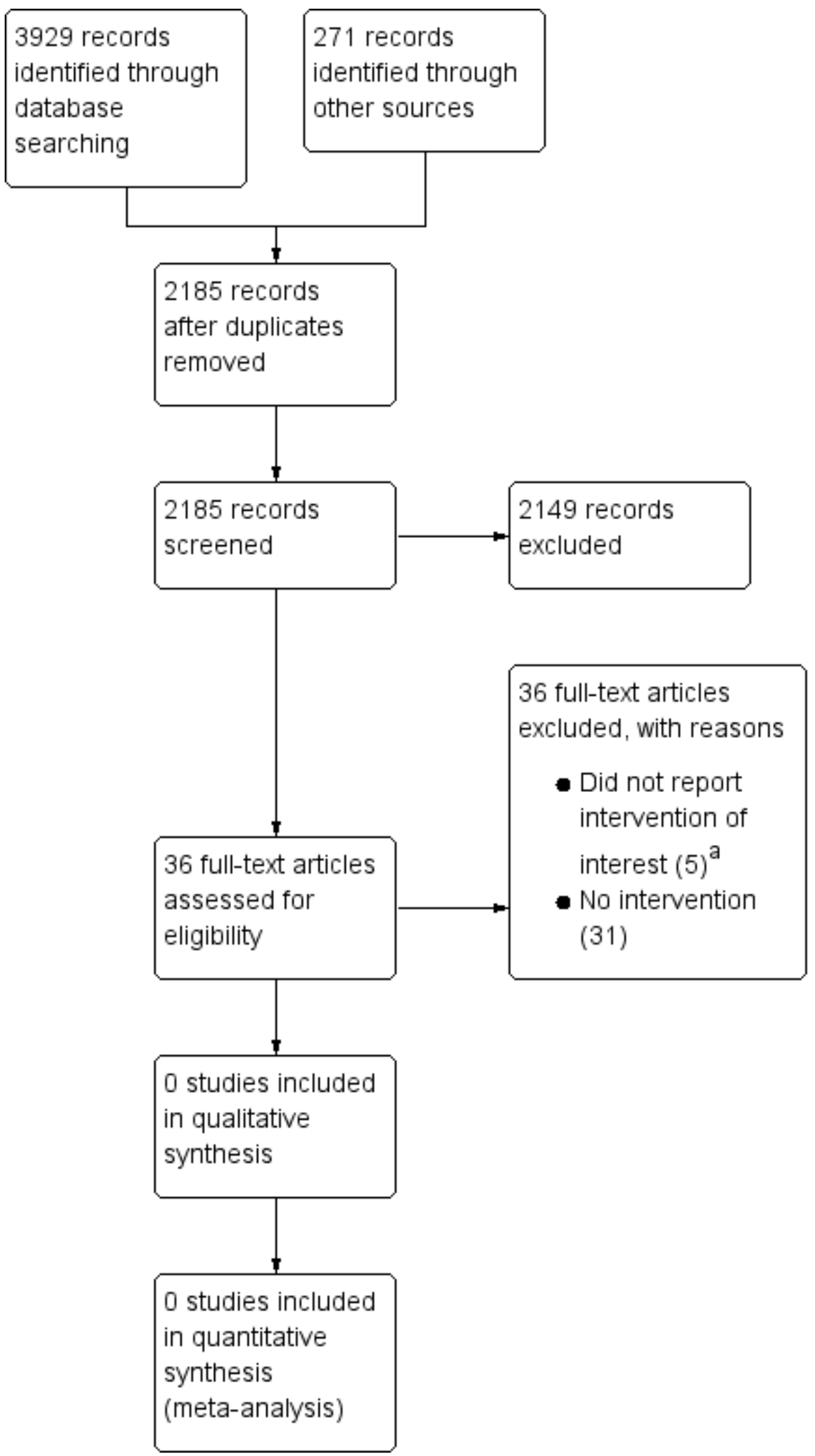




\section{Included studies}

We found no studies that met the inclusion criteria for this review.

\section{Excluded studies}

The Characteristics of excluded studies table shows all records that we excluded from this systematic review.

\section{Studies awaiting classification}

No studies are awaiting classification.

\section{Ongoing studies}

We found no ongoing studies.

\section{Risk of bias in included studies}

We found no studies that met the inclusion criteria for this review.

\section{Allocation}

We found no studies.

\section{Blinding}

We found no studies.

\section{Incomplete outcome data}

We found no studies.

\section{Selective reporting}

We found no studies.

\section{Other potential sources of bias}

We found no studies.

\section{Effects of interventions}

We found no studies that met the inclusion criteria for this review.

\section{DISCUSSION}

\section{Summary of main results}

Our review identified no eligible studies that assessed the effectiveness of restriction of physical means of access as a method of preventing suicide on roads.

\section{Overall completeness and applicability of evidence}

We were aware of the limited nature of the research around road traffic suicides beforehand, so we ensured we accessed the maximum amount of literature possible on this topic. This included designing a broad search strategy incorporating a wide range of search terms, searching a wide range of databases - including specialised transportation databases - and contacting subject experts for information on unpublished or ongoing studies. It is unlikely that we missed any relevant studies

\section{Quality of the evidence}

We found no studies that met the inclusion criteria for this review.

\section{Potential biases in the review process}

Although we conducted searches of grey literature, there is a possibility that potentially eligible studies may have been missed.

\section{Agreements and disagreements with other studies or reviews}

We are not aware of any other reviews that specifically address this intervention in a road setting. Other reviews have focused on the epidemiology of road traffic suicides (Routley 2003; Pompili 2012), or sought to establish a link between single-car accident drivers and suicidal intent (Pompili 2006).

\section{AUTHORS' CONCLUSIONS}

\section{Implications for practice}

This review identified no eligible studies that assessed the effectiveness of restriction of physical means of access as a method of preventing suicide on roads. This does not mean that means restriction interventions would not work in a road traffic setting. Previous research has shown that installation of physical barriers and fencing at high-risk jumping sites, especially bridges and railways, could be effective at reducing the number of suicides at these sites (Pirkis 2015; Ueda 2015; Okolie 2020). Since barriers and fences provide a physical obstruction to prevent individuals from jumping off or onto structures, this approach may also be relevant in the prevention of suicides on actual road networks - particularly pedestrian suicide - by restricting pedestrian access to road networks. In situations where physical barriers are not appropriate, other measures such as painted lines and cross-hatchings have been used to mark areas that are unsafe to enter (Public Health England 2015). Anyone crossing such a boundary will be conspicuous, and this may be enough to deter suicidal individuals or offer an opportunity for third-party intervention. Similarly, the installation of blue light-emitting diode (LED) lamps at railway crossings and platforms has been shown to decrease the number of suicides at these sites (Matsubayashi 2013). This intervention could be applicable on road networks especially those identified as high-risk sites.

Measures suggested for preventing vehicle driver suicides include the use of alcohol ignition interlock devices, intelligent speed adaptation (ISA) systems, the use of electronic driving licences (Smart licences), driver monitoring systems, and the employment of automatic emergency systems (Routley 2003; WHO 2017). Some in-vehicle measures such as seat-belts, airbags, driver assistant systems, and anticollision radars may offer some protection, but these systems can be overridden or ignored by a driver intent on taking their own life and are, therefore, unlikely to be effective at preventing driver suicides (Routley 2003).

Little is known currently about road traffic suicides in comparison to other methods of suicides. Determining suicidal intent is a key issue, therefore clear objective criteria to determine ascertainment is necessary in order to scale up and study this method more accurately. In the absence of any substantial evidence, we advocate for more awareness on road traffic suicides and its inclusion in future government suicide prevention policies. 


\section{Implications for research}

The lack of eligible studies emphasises the need for future robust studies that aim to investigate the effectiveness of interventions to prevent road traffic suicides. This would be particularly important for in-vehicle technologies in which an override of the system is not possible, such as in fully autonomous (driverless/self-drive) vehicles. However, there are ethical, legal, and safety concerns with self-driving technology (Hevelke 2015). Overall, a detailed knowledge and further understanding of this suicide method is required for prevention efforts. This would require improvements to existing incident-reporting systems, cross-sector collaboration, and data-sharing processes. Currently, most national mental health and public health strategies on suicide refer to railways but not roads. Consideration of suicide on roads in future government suicide prevention policies is needed. Reliable methods of studying road traffic suicides are also important in determining suicide ascertainment. This could be accomplished by the routine investigation of every road traffic fatality by an interdisciplinary team (Hernetkoski 1998), including complete autopsies (both psychological and forensic) routinely performed for fatal single-vehicle, single-occupant vehicle incidents (Pompili 2012). Furthermore, an investigation into any factors in play in determining why an individual would contemplate using road traffic collision as a means of suicide is required. This is especially important because of the widespread availability of motor vehicles. One study exploring factors influencing and discouraging the decision to attempt suicide on railway networks found that people chose this method because railway settings were easy to access and because of an inaccurate perception of certain and quick lethality (Marzano 2019). A study incorporating participants who had survived a suicide attempt on the road would be useful to gain insights that could aid in prevention.

Further research is required for the identification of individuals who may be about to make a suicide attempt on a road. Previous research on railways suggests that there are several behaviours that may be identifiable in the moments leading up to a suicide or suicide attempt which may present opportunities for intervention (Mackenzie 2018). Driver monitoring systems currently being developed to reduce vehicle speed on detection of risky patterns of driving may have the potential for application in preventing driver suicide (Routley 2003). In addition, most research on this topic normally focuses only on people who died and not on survivors of suicide attempts. Focusing only on suicide incidents could underestimate the true scale of the problem and overall impacts of interventions on suicidal behaviour. Further research incorporating suicide attempts is, therefore, required in this regard, as well as to explore various health-related issues in suicide survivors which could aid in prevention efforts. Other factors such as the 'Werther Effect' need to be investigated (Jonas 1992). Prominent media coverage and style of reporting may contribute to imitation or contagion and thus lead to an increase in use of this method. In addition, identification of the road networks and locations where road traffic suicides occur more frequently is required in order to target the appropriate interventions. Finally, while it may not be ethical or practical to conduct RCTs on interventions to reduce suicide on roads, further well-designed high-quality observational studies are required to further evaluate the effectiveness of these interventions. Controlled before-after studies would provide a higher level of confidence in the findings around ruling out possible influence of secular trends and co-occurring interventions.

\section{ACKNOWLEDGEMENTS}

The review authors thank the Cochrane Common Mental Disorders Group for providing support for this suite of reviews, and Swansea University Medical School and Public Health Wales for funding CO's post.

The authors and the Cochrane Common Mental Disorders Editorial Team are grateful to the peer reviewers for their time and comments including: Siobhan O'Neill, Katrina Witt and Gillian Worthy. They would also like to thank Cochrane Copy Edit Support for the team's help.

CRG funding acknowledgement: the National Institute for Health Research (NIHR) is the largest single funder of the Cochrane Common Mental Disorders Group.

Disclaimer: the views and opinions expressed therein are those of the review authors and do not necessarily reflect those of the NIHR, the National Health Service, or the Department of Health and Social Care. 


\section{R E F E R E N C E S}

\section{References to studies excluded from this review}

Austin 2013 \{published data only\}

Austin AE, van den Heuvel C, Byard R. Suicide and fatal single occupant motor vehicle collisions. Australian Journal of Forensic Sciences 2013;45:43-8.

\section{Barranco 2018 \{published data only\}}

Barranco R, Caputo F, Bonsignore A, Fraternali Orcioni G, Ventura $F$. A rare vehicle-assisted ligature hanging: suicide at the wheel. American Journal of Forensic Medicine \& Pathology 2018;39(1):69-72.

\section{Beautrais 2001 \{published data only\}}

Beautrais AL. Effectiveness of barriers at suicide jumping sites: a case study. Australian \& New Zealand Journal of Psychiatry 2001;35(5):557-62.

\section{Beautrais 2009 \{published data only\}}

Beautrais AL, Gibb SJ, Fergusson DM, Horwood LJ, Larkin GL. Removing bridge barriers stimulates suicides: an unfortunate natural experiment. Australian \& New Zealand Journal of Psychiatry 2009;43(6):495-7.

\section{Beskow 2013 \{published data only\}}

Beskow J, Andersson AL, Lindberg E, Svensson K, Tingvall C. The Swedish Transport Administration, first authority with suicide prevention program. Lakartidningen 2013;110(17-18):890.

\section{Bjornstig 2008 \{published data only\}}

Bjornstig U, Bjornstig J, Eriksson A. Passenger car collision fatalities - with special emphasis on collisions with heavy vehicles. Accident Analysis \& Prevention 2008;40(1):158-66.

\section{Boglioli 1988 \{published data only\}}

Boglioli LR, Taff ML, Green AS, Lukash LI, Lane R. A bizarre case of vehicular suicide. American Journal of Forensic Medicine \& Pathology 1988;9(2):169-78.

\section{Conner 2017 \{published data only\}}

Conner KR, Lathrop S, Caetano R, Wiegand T, Kaukeinen K, Nolte KB. Presence of alcohol, cocaine, and other drugs in suicide and motor vehicle crash decedents ages 18 to 54 . Alcoholism, Clinical and Experimental Research 2017;41(3):571-5.

\section{Damian 1973 \{published data only\}}

Damian N, Rascanu R. Aspects of suicide in automobile drivers. Neurologia, Psihiatria, Neurochirurgia 1973;18(3):263-8.

Drazkowski 2011 \{published data only\} Drazkowski JF, Sirven JI. Motor vehicle crashes, suicides, and assaults: the dangers of epilepsy? Neurology 2011;76(9):770-1.

\section{Gauthier 2015 \{published data only\}}

Gauthier S, Reisch T, Ajdacic-Gross V, Bartsch C. Road traffic suicide in Switzerland. Traffic Injury Prevention 2015;16(8):768-72.
Grimmond 1974 \{published data only\}

Grimmond BB. Suicide at the wheel. New Zealand Medical Journal 1974;80(521):90-4.

Gussen 1971 \{published data only\}

Gussen J. Drivers injured in one-car accidents and survivors of serious suicide attempts. Accident; Analysis and Prevention 1971;3(4):269-76

Hamalainen 1973 \{published data only\}

Hamalainen K. Automobile accidents as self-destructive behavior: a study of the accidents of drinking-drivers. Psychiatria Fennica 1973:147-51.

Harrison 2017 \{published data only\}

Harrison K, Parliamentary Advisory Council for Transport Safety. Suicide on UK roads: lifting the lid, 2017. www.pacts.org.uk/wp-content/uploads/ PACTS_Report_SuicidesUKRoads_LOWRES.pdf (accessed prior to 1 September 2020).

Hejna 2012 \{published data only\}

Hejna P, Havel R. Vehicle-assisted decapitation: a case report. American Journal of Forensic Medicine and Pathology 2012;33(1):73-5.

Hernetkoski 1998 \{published data only\}

Hernetkoski K, Keskinen E. Self-destruction in Finnish motor traffic accidents in 1974-1992. Accident Analysis \& Prevention 1998;30(5):697-704.

\section{Hernetkoski 2009 \{published data only\}}

Hernetkoski KM, Keskinen EO, Parkkari IK. Driver suicides in Finland - are they different in Northern and Southern Finland? International Journal of Circumpolar Health 2009;68(3):249-60.

Hingson 1985 \{published data only\} Hingson R, Merrigan D, Heeren T. Effects of Massachusetts raising its legal drinking age from 18 to 20 on death from teenage homicide, suicide, and nontraffic accidents. Pediatric Clinics of North America 1985;32(1):221-32.

Langer 1979 \{published data only\}

Langer R. An unusual suicidal attempt. Wiener Medizinische Wochenschrift 1979;129(20):566-7.

Manaouil 2015 \{published data only\} Manaouil C. The vehicle driver is it as dangerous as an airline pilot? Presse Medicale 2015;44(9):913-5.

Martiniuk 2009 \{published data only\}

Martiniuk AL, Ivers RQ, Glozier N, Patton GC, Lam LT, Boufous S, et al. Self-harm and risk of motor vehicle crashes among young drivers: findings from the DRIVE study. Canadian Medical Association Journal 2009;181(11):807-12. 
Martiniuk 2010 \{published data only\}

Martiniuk AL, Ivers RQ, Glozier N, Patton GC, Lam LT, Boufous S, et al. Self-harm and risk of motor vehicle crashes in youth: the Drive Prospective Cohort Study. Injury Prevention 2010;16:A100.

\section{Milner 2015 \{published data only\}}

Milner A, Page K, LaMontagne AD. Suicide among male road and rail drivers in Australia: a retrospective mortality study. Road and Transport Research 2015;24(2):26-31.

Mishara 2007 \{published data only\}

Mishara BL. Railway and metro suicides: understanding the problem and prevention potential. Crisis 2007;28(1):36-43.

\section{Murray 2007 \{published data only\}}

Murray D, De Leo D. Suicidal behavior by motor vehicle collision. Traffic Injury Prevention 2007;8(3):244-7.

\section{Noyes 1985 \{published data only\}}

Noyes R. Motor vehicle accidents related to psychiatric impairment. Psychosomatics 1985;26(7):569-80.

O'Carrol 1994 \{published data only\}

O'Carroll PW, Silverman MM, Berman AL. Community suicide prevention: the effectiveness of bridge barriers. Suicide \& Lifethreatening Behavior 1994;24(1):89-99.

\section{Ohberg 1997 \{published data only\}}

Ohberg A, Penttila A, Lonnqvist J. Driver suicides. British Journal of Psychiatry 1997;171:468-72.

\section{Pridmore 2017 \{published data only\}}

Pridmore S, Varbanov S, Sale I, Ahmadi J. Does driver suicide occur in Iran? Iranian Journal of Psychiatry and Behavioral Sciences 2017;11:e4917.

\section{Razaeian 2008 \{published data only\}}

Razaeian M, Mohammadi M, Akbari M, Maleki M. The most common method of suicide in Tehran 2000-2004: implications for prevention. Crisis 2008;29(3):164-6.

\section{Sansone 2010 \{published data only\}}

Sansone RA, Lam C, Wiederman MW. History of attempted suicide and reckless driving: a cross-sectional study in primary care. Primary Care Companion to the Journal of Clinical Psychiatry 2010;12(4):e1-e4.

\section{Schmidt 1977 \{published data only\}}

Schmidt CW, Shaffer JW, Zlotowitz HI, Fisher RS. Suicide by vehicular crash. American Journal of Psychiatry 1977;134(2):175-8.

\section{Sinyor 2010 \{published data only\}}

Sinyor M, Levitt AJ. Effect of a barrier at Bloor Street Viaduct on suicide rates in Toronto: natural experiment. BMJ 2010;341:c2884.

\section{Sinyor 2017 \{published data only\}}

Sinyor M, Schaffer A, Redelmeier DA, Kiss A, Nishikawa Y, Cheung $\mathrm{AH}$, et al. Did the suicide barrier work after all?
Revisiting the Bloor Viaduct natural experiment and its impact on suicide rates in Toronto. BMJ Open 2017;7:e015299.

Wyatt 2009 \{published data only\}

Wyatt JP, Squires T, Collis S, Broadley R. Road traffic suicides. Journal of Forensic and Legal Medicine 2009;16(4):212-4.

\section{Additional references}

\section{Andersson 2015}

Andersson A, Svensson K. Fatalities in road traffic, a result of accidents or suicides. Journal of Local and Global Health Science 2015;2015(2):e27.

\section{Balshem 2011}

Balshem H, Helfand M, Schünemann HJ, Oxman AD, Kunz R, Brozek J, et al. GRADE guidelines: 3 . Rating the quality of evidence. Journal of Clinical Epidemiology 2011;64:401-6.

\section{Daigle 2005}

Daigle MS. Suicide prevention through means restriction: assessing the risk of substitution: a critical review and synthesis. Accident; Analysis and Prevention 2005;37(4):625-32.

\section{Department for Transport 2018}

Department for Transport. Reported Road Casualties Great Britain: 2017 annual report - moving Britain ahead, 2018. assets.publishing.service.gov.uk/government/uploads/ system/uploads/attachment_data/file/755698/rrcgb-2017.pdf (accessed prior to 1 September 2020).

\section{Egger 1997}

Egger M, Smith GD, Schneider M, Minder C. Bias in meta-analysis detected by a simple, graphical test. BMJ 1997;315(7109):629-34

\section{Florentine 2010}

Florentine J, Crane C. Suicide prevention by limiting access to methods: a review of theory and practice. Social Science \& Medicine 2010;70(10):1626-32.

\section{Geulayov 2016}

Geulayov G, Kapur N, Turnbull P, Clements C, Waters K, Ness J, et al. Epidemiology and trends in non-fatal self-harm in three centres in England, 2000-2012: findings from the Multicentre Study of Self-harm in England. BMJ Open 2016;6(e010538):1-8.

\section{Hawkins 2007}

Hawkins LC, Edwards JN, Dargan PI. Impact of restricting paracetamol pack sizes on paracetamol poisoning in the United Kingdom. Drug Safety 2007;30(6):465-79.

\section{Hawton 2001}

Hawton K, Townsend E, Deeks J, Appleby L, Gunnell D, Bennewith $\mathrm{O}$, et al. Effects of legislation restricting pack sizes of paracetamol and salicylate on self poisoning in the United Kingdom: before and after study. BMJ 2001;322(7296):1203. 


\section{Hawton 2005}

Hawton K. Restriction of access to methods of suicide as a means of suicide prevention. In: Prevention and Treatment of Suicidal Behaviour from Science to Practice. Oxford (UK): Oxford University Press, 2005:279-91.

\section{Hawton 2007}

Hawton K. Restricting access to methods of suicide - rationale and evaluation of this approach to suicide prevention. Crisis 2007;28:4-9.

\section{Hawton 2008}

Hawton $\mathrm{K}$, Harriss $\mathrm{L}$. The changing gender ratio in occurrence of deliberate self-harm across the lifecycle. Crisis 2008;29(1):4-10.

\section{Hawton 2009}

Hawton K, van Heeringen K. Suicide. Lancet 2009;373(9672):1372-81.

\section{Hawton 2016}

Hawton K, Witt KG, Taylor Salisbury TL, Arensman E, Gunnell D, Hazell P, et al. Psychosocial interventions for self-harm in adults. Cochrane Database of Systematic Reviews 2016, Issue 5. Art. No: CD012189. [DOI: 10.1002/14651858.CD012189]

\section{Hevelke 2015}

Hevelke A, Nida-Rümelin J. Responsibility for crashes of autonomous vehicles: an ethical analysis. Science and Engineering Ethics 2015;21(3):619-30.

\section{Higgins 2019}

Higgins JP, Thomas J, Chandler J, Cumpston M, Li T, Page MJ, Welch VA, editor(s). Cochrane Handbook for Systematic Reviews of Interventions version 6.0 (updated August 2019). Cochrane, 2019. Available from www.training.cochrane.org/handbook.

\section{Highways England 2017}

Highways England. Suicide prevention strategy - our approach, 2017. assets.publishing.service.gov.uk/government/uploads/ system/uploads/attachment_data/file/675754/N170235__Suicide_Prevention_Strategy.pdf (accessed prior to 1 September 2020).

\section{Jonas 1992}

Jonas K. Modeling and suicide - a test of the Werther effect. British Journal of Social Psychology 1992;31:295-306.

\section{Lester 1993}

Lester D. Suicide from bridges in Washington, DC. Perceptual and Motor Skills 1993;77(2):534.

\section{Mackenzie 2018}

Mackenzie JM, Borrill J, Hawkins E, Fields B, Kruger I, Noonan I, et al. Behaviours preceding suicides at railway and underground locations: a multimethodological qualitative approach. BMJ Open 2018;8(4):8.

\section{Mann 2005}

Mann JJ, Apter A, Bertolote J, Beautrais A, Currier D, Haas A, et al. Suicide prevention strategies: a systematic review. JAMA 2005;294(16):2064-74.

\section{Marzano 2019}

Marzano L, Mackenzie J, Kruger I, Borrill J, Fields B. Factors deterring and prompting the decision to attempt suicide on the railway networks: findings from 353 online surveys and 34 semi-structured interviews. British Journal of Psychiatry 2019;215(4):582-7.

\section{Matsubayashi 2013}

Matsubayashi T, Sawada Y, Ueda M. Does the installation of blue lights on train platforms prevent suicide? A before-and-after observational study from Japan. Journal of Affective Disorders 2013;147(1):385-8.

\section{NICE 2011}

National Institute for Health and Care Excellence. Self-harm in over 8s: long-term management. Clinical guideline [CG133], 2011. www.nice.org.uk/guidance/cg133 (accessed prior to 1 September 2020).

\section{O'Carroll 1994}

O'Carroll PW, Silverman MM. Community suicide prevention: the effectiveness of bridge barriers. Suicide \& Life-threatening Behavior 1994;24(1):89-99.

\section{Okolie 2020}

Okolie C, Wood S, Hawton K, Kandalama U, Glendenning AC, Dennis $M$, et al. Means restriction for the prevention of suicide by jumping. Cochrane Database of Systematic Reviews 2020, Issue 2. Art. No: CD013543. [DOI: 10.1002/14651858.CD013543]

\section{Pirkis 2013}

Pirkis J, Spittal MJ, Cox G, Robinson J, Cheung YT, Studdert D. The effectiveness of structural interventions at suicide hotspots: a meta-analysis. International Journal of Epidemiology 2013;42(2):541-8.

\section{Pirkis 2015}

Pirkis J, Too LS, Spittal MJ, Krysinska K, Robinson J, Cheung YT. Interventions to reduce suicides at suicide hotspots: a systematic review and meta-analysis. Lancet Psychiatry 2015;2(11):994-1001.

\section{Pompili 2012}

Pompili M, Serafini G, Innamorati M, Montebovi F, Palermo M, Campi S, et al. Car accidents as a method of suicide: a comprehensive overview. Forensic Science International 2012;223(1-3):1-9.

\section{Pompili 2006}

Pompili M, Girardi P, Tatarelli G, Taterelli R. Suicidal intent in single-car accident drivers: review and new preliminary findings. Crisis 2006;27(2):92-9.

\section{Public Health England 2015}

Public Health England. Preventing suicides in public places: a practice resource, 2015. www.gov.uk/government/publications/ suicide-prevention-suicides-in-public-places (accessed prior to 1 September 2020). 


\section{RevMan Web 2019 [Computer program]}

The Cochrane Collaboration Review Manager Web (RevMan Web). Copenhagen: The Nordic Cochrane Centre: The Cochrane Collaboration, 2019. Available at revman.cochrane.org.

\section{Routley 2003}

Routley V, Staines C, Brennan C, Haworth N, Ozanne-Smith J. Suicide and natural deaths in road traffic: review. Monash University Accident Research Centre 2003.

\section{Schünemann 2011}

Schünemann HJ, Oxman AD, Vist GE, Higgins JP, Deeks JJ, Glasziou $P$, et al. Chapter 12: Interpreting results and drawing conclusions. In: Higgins JP, Green S, editor(s). Cochrane Handbook for Systematic Reviews of Interventions Version 5.1.0 (updated March 2011). The Cochrane Collaboration, 2011. Available from handbook.cochrane.org.

\section{Shemilt 2019}

Shemilt I, Aluko P, Graybill E, Craig D, Henderson C, Drummond $\mathrm{M}$, et al. Chapter 20: Economic evidence. In: Higgins JP, Thomas J, Chandler J, Cumpston M, Li T, Page MJ, et al, editor(s). Cochrane Handbook for Systematic Reviews of Interventions version 6.0 (updated August 2019). Cochrane, 2019. www.training.cochrane.org/handbook.

\section{Sinclair 2010}

Sinclair JM, Hawton K, Gray A. Six year follow-up of a clinical sample of self-harm patients. Journal of Affective Disorders 2010;121(3):247-52.

\section{Spittal 2015}

Spittal MJ, Pirkis J, Gurrin LC. Meta-analysis of incidence rate data in the presence of zero events. BMC Medical Research Methodology 2015;15:42.

\section{Sterne 2016a}

Sterne JA, Hernán MA, Reeves BC, Savović J, Berkman ND, Viswanathan $\mathrm{M}$, et al. ROBINS-I: a tool for assessing risk of bias in non-randomised studies of interventions. BMJ 2016;355:i4919.

\section{Sterne 2016b}

Sterne JA, Higgins JP, Elbers RG, Reeves BC, The Development Group for ROBINS-I. Risk of bias in non-randomized studies of interventions (ROBINS-I): detailed guidance, 2016. www.riskofbias.info (accessed prior to 1 September 2020).

\section{Turecki 2016}

Turecki G, Brent DA. Suicide and suicidal behaviour. Lancet 2016;387:1227-39.

\section{Ueda 2015}

Ueda M, Sawada Y, Matsubayashi T. The effectiveness of installing physical barriers for preventing railway suicides and accidents: evidence from Japan. Journal of Affective Disorders 2015;178:1-4.

\section{WHO 2014}

World Health Organization. Preventing suicide: a global imperative, 2014. www.who.int/mental_health/suicideprevention/world_report_2014/en/ (accessed prior to 1 September 2020).

\section{WHO 2017}

World Health Organization. Save LIVES - a road safety technical package, 2017. apps.who.int/iris/handle/10665/255199 (accessed prior to 1 September 2020).

\section{WHO 2018}

World Health Organization. Suicide: fact sheet [online], 2018. www.who.int/en/news-room/fact-sheets/detail/suicide (accessed 15 April 2020).

\section{WHO 2019}

World Health Organization. Suicide in the world: global health estimates, 2019. www.who.int/publicationsdetail/suicide-inthe-world (accessed prior to 1 September 2020).

\section{Yip 2012}

Yip PS, Caine E, Yousuf S, Chang SS, Wu KC, Chen YY. Means restriction for suicide prevention. Lancet 2012;379:2393-9.

\section{References to other published versions of this review John 2018}

John A, Hawton K, Okolie C, Dennis M, Price SF, Lloyd K. Means restriction for the prevention of suicide: generic protocol. Cochrane Database of Systematic Reviews 2018, Issue 4. Art. No: CD012995. [DOI: 10.1002/14651858.CD012995]

\section{CHARACTERISTICS OF STUDIES}

Characteristics of excluded studies [ordered by study ID]

\begin{tabular}{ll}
\hline Study & Reason for exclusion \\
\hline Austin 2013 & $\begin{array}{l}\text { No intervention reported. Focus was on determining the demographic profile of suicide cases that } \\
\text { occurred by single motor vehicle collision. }\end{array}$ \\
\hline Barranco 2018 & No intervention reported. \\
\hline Beautrais 2001 & Intervention not specific to road networks. Focus on suicide by jumping. \\
\hline
\end{tabular}




\begin{tabular}{|c|c|}
\hline Study & Reason for exclusion \\
\hline Beautrais 2009 & Intervention not specific to road networks. Focus on suicide by jumping. \\
\hline Beskow 2013 & No intervention reported. \\
\hline Bjornstig 2008 & No intervention reported. Focus was on car collisions involving heavy vehicles. \\
\hline Boglioli 1988 & No intervention reported. Case report. \\
\hline Conner 2017 & $\begin{array}{l}\text { No intervention reported. Focus was on the presence of alcohol and drugs in suicide and motor ve- } \\
\text { hicle crash decedents. }\end{array}$ \\
\hline Damian 1973 & No intervention reported. \\
\hline Drazkowski 2011 & No intervention reported. Editorial. \\
\hline Gauthier 2015 & Epidemiological study. No intervention reported. \\
\hline Grimmond 1974 & No intervention reported. \\
\hline Gussen 1971 & No intervention reported. \\
\hline Hamalainen 1973 & No intervention reported. \\
\hline Harrison 2017 & No intervention reported. \\
\hline Hejna 2012 & No intervention reported. Case report. \\
\hline Hernetkoski 2009 & No intervention reported. \\
\hline Hernetkoski 1998 & Epidemiological study. No intervention reported. \\
\hline Hingson 1985 & No intervention reported. \\
\hline Langer 1979 & No intervention reported. \\
\hline Manaouil 2015 & No intervention reported. \\
\hline Martiniuk 2009 & No intervention reported. \\
\hline Martiniuk 2010 & No intervention reported. \\
\hline Milner 2015 & No intervention reported. \\
\hline Mishara 2007 & No intervention reported. Focus on railway and metro (underground and subway) suicides. \\
\hline Murray 2007 & No intervention reported. \\
\hline Noyes 1985 & No intervention reported. \\
\hline O'Carrol 1994 & Intervention not specific to road networks. Focus on suicide by jumping. \\
\hline Ohberg 1997 & Epidemiological study. No intervention reported. \\
\hline Pridmore 2017 & No intervention reported. \\
\hline
\end{tabular}




\begin{tabular}{ll}
\hline Study & Reason for exclusion \\
\hline Razaeian 2008 & Focus on methods of suicide. No intervention reported. \\
\hline Sansone 2010 & No intervention reported. \\
\hline Schmidt 1977 & Epidemiological study. No intervention reported. \\
\hline Sinyor 2010 & Intervention not specific to road networks. Focus on suicide by jumping. \\
\hline Sinyor 2017 & Intervention not specific to road networks. Focus on suicide by jumping. \\
\hline Wyatt 2009 & Epidemiological study. No intervention reported. \\
\hline
\end{tabular}

\section{APPENDICES}

\section{Appendix 1. The Cochrane Library search \\ The Cochrane Library, Issue 3 of 12, 2020}

Search Manager: ((hotspot* or "hot spot*" or carriageway* or motorway* or highway or road or roads or roadway* or automobile* or driver $^{\star}$ or vehicle ${ }^{\star}$ or vehicular or motorcar ${ }^{\star}$ or streetcar ${ }^{\star}$ or car or cars or motorbike* or bike* or cyclist* or bicycl ${ }^{\star}$ or bus or buses or truck or trucks or lorry or lorries or van or vans or pedestrian* or HGV or traffic or jump* or leap* or height* or drive or driver* or driving or drove or "cash into" or "step into" or "stepping into" or "step in front" or "stepping in front" or "step out" or "stepping out" or "fall into" or "falling into" or "fall in front" or "falling in front" or "fall out" or "falling out" or "fall from" or "falling from") AND (fenc* or barrier* or parapet or net or nets or sign or signs or signage or signpost* or poster* or surveillance* or CCTV or camera* or video* or patrol* or interlock* or lighting or lights or "means restriction" or ((limit* or restrict*) NEAR (access* or mean or means or method or methods)) or (reduc* next risk) or "environment" design" or "environment* planning" or "built environment" or "crisis intervention" or "architectural accessibility" or "safety management" or "traffic safety" or (prevent* and suicid*) or ((preventive or prevention) and (intervention* or program*)) or (prevention NEAR control)) AND suicid $\left.{ }^{\star}\right): t i, a b, k w$ OR ((automobile* or driver* or vehicle* or vehicular or road or roads or traffic) NEXT suicid"):ti,ab,kw OR ((automobile* or "motor vehicle*" or traffic) and suicid*):kw

\section{Appendix 2. Ovid MEDLINE, Embase, and PsycINFO search strategies}

Ovid Cross-Search: APA PsycInfo <1806 to March week 4 2020>, Embase <1974 to 2020 week 13>, Ovid MEDLINE(R) and Epub Ahead of Print, In-Process \& Other Non-Indexed Citations and Daily <1946 to 26 March 2020>

1 (hotspot? or hot spot?).mp.

2 (carriageway? or motorway? or highway? or road or roads or roadway?).mp.

3 (automobile* or driver* or vehicle* or vehicular or motorcar? or streetcar? or car or cars or motorbike? or bike? or cyclist? or bicycl* or bus or buses or truck or trucks or lorry or lorries or van or vans or pedestrian* or HGV or traffic).mp.

4 (jump* or leap* or height? or drive or driver? or driving or drove).mp.

5 ("crash into" or "step into" or "stepping into" or "step in front" or "stepping in front" or "step out" or "stepping out").ab.

6 ("fall into" or "falling into" or "fall in front" or "falling in front" or "fall out" or "falling out" or "fall from" or "falling from").ab.

7 or $1-6$

8 (fenc ${ }^{\star}$ or barrier ${ }^{\star}$ or parapet or net or nets or sign or signs or signage or signpost? or poster ${ }^{\star}$ or surveillance* or CCTV or camera? or video? or patrol ${ }^{\star}$ or interlock* or lighting or lights).mp.

9 means restriction?.mp.

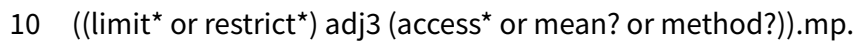

11 Risk Reduction Behavior/ or Risk Reduction/ 
12 environment design/ or exp environmental planning/ or built environment/

$13{ }^{*}$ Crisis Intervention/

14 Architectural Accessibility/

15 Safety Management/ or traffic safety/

16 ((prevent ${ }^{\star}$ and suicid $\left.{ }^{\star}\right)$ or ((preventive or prevention) and (intervention* or program $\left.\left.{ }^{\star}\right)\right)$ or (prevention adj2 control)).mp.

17 or/8-16

18 suicide/ or suicidal ideation/ or suicide, attempted/ or suicide, completed/

19 suicidal behavior/ or suicide/ or suicide attempt/

20 suicide/ or suicidality/

21 suicid ${ }^{\star} . t i$. or (prevent ${ }^{\star}$ adj5 suicid $\left.{ }^{\star}\right) . a b, k f, k w, i d$.

22 or $/ 18-21$

237 and 17 and 22

24 ((automobile? or driver? or vehicle? or vehicular or road? or traffic) adj suicide?).mp.

25 ((automobile? or motor vehicle?) and suicide?).hw.

26 or $/ 23-25$

27 Conference Abstract.pt,st.

$28 \quad 26 \operatorname{not} 27$

29 ((hotspot? or hot spot? or carriageway? or motorway? or highway? or road or roads or roadway? or automobile* or driver ${ }^{\star}$ or vehicle or vehicular or motorcar? or streetcar? or car or cars or motorbike? or bike? or cyclist? or bicycl* or bus or buses or truck or trucks or lorry or lorries or van or vans or pedestrian* or HGV or traffic) and suicid*).ti.

30 (24 or 25 or 29 ) and 27

3128 or 30

\section{Appendix 3. TRID Database search}

TRID Database (incorporating the TRB's Transportation Research Information Services (TRIS) Database and the OECD's Joint Transport Research Centre's International Transport Research Documentation (ITRD) Database)

Search: (suicide or suicides or suicidal)

\section{H I S T ORY}

Review first published: Issue 9, 2020

\section{CONTRIBUTIONSOF AUTHORS}

AJ conceived the concept for the suite of reviews.

AJ, MD, SP, KH, and KL developed the basis for the protocol and review.

$\mathrm{AJ}$ and $\mathrm{CO}$ were involved in writing the protocol and review.

AJ and CO participated in searching, identifying and assessing studies; and planned to extract data and perform analyses.

$\mathrm{MD}, \mathrm{SP}, \mathrm{KH}$, and $\mathrm{KL}$ provided general advice on the protocol and review. 


\section{DECLARATIONS OF INTEREST}

$\mathrm{KL}$ and AJ are co-directors the Cochrane Satellite for Suicide and Self-Harm portion of the Cochrane Common Mental Disorders Group. SP and $\mathrm{CO}$ are members.

$\mathrm{KH}$ has been involved in trials and studies related to means restriction of paracetamol/aspirin and locked pesticide boxes in low- and middle-income countries, and will play no part in any decisions related to any of his studies.

MD has no known conflicts of interest to declare.

\section{SOURCES OF SUPPORT}

\section{Internal sources}

- Swansea University, UK

\section{External sources}

- Public Health Wales, UK

\section{N DEX TERMS}

\section{Medical Subject Headings (MeSH)}

Accidents, Traffic [ ${ }^{\star}$ prevention \& control] [psychology]; Risk Factors; Suicide [* prevention \& control]

\section{MeSH check words}

Humans 